
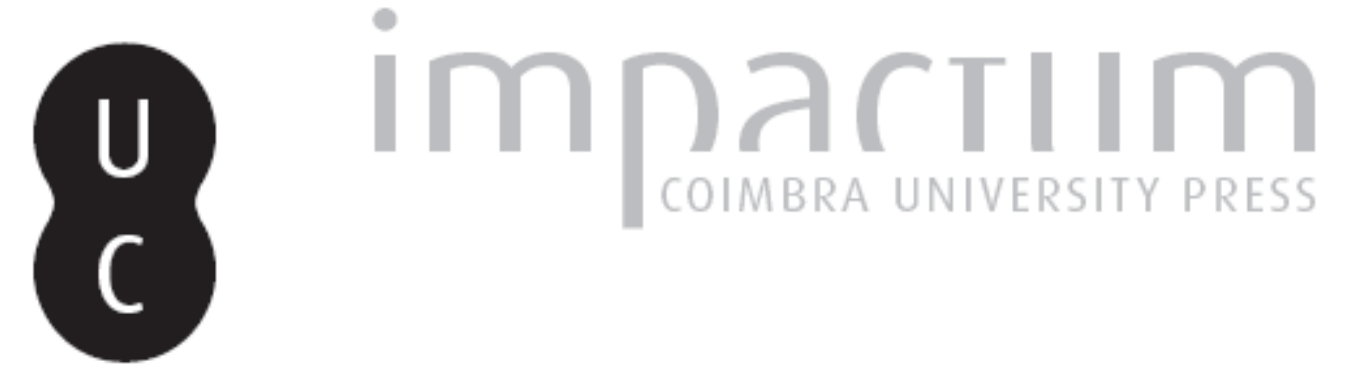

\title{
Naturalismo semântico: uso e aceitação
}

Autor(es): $\quad$ Carmo, Juliano Santos do

Publicado por: $\begin{aligned} & \text { Universidade Católica de Petrópolis; Instituto Brasileiro de Informação } \\ & \text { em Ciência e Tecnologia }\end{aligned}$

URL

persistente:

URI:http://hdl.handle.net/10316.2/33025

DOI:

DOI:http://dx.doi.org/10.14195/1984-6754_4-1_5

Accessed : $\quad$ 26-Apr-2023 10:44:14

A navegação consulta e descarregamento dos títulos inseridos nas Bibliotecas Digitais UC Digitalis, UC Pombalina e UC Impactum, pressupõem a aceitação plena e sem reservas dos Termos e Condições de Uso destas Bibliotecas Digitais, disponíveis em https://digitalis.uc.pt/pt-pt/termos.

Conforme exposto nos referidos Termos e Condições de Uso, o descarregamento de títulos de acesso restrito requer uma licença válida de autorização devendo o utilizador aceder ao(s) documento(s) a partir de um endereço de IP da instituição detentora da supramencionada licença.

Ao utilizador é apenas permitido o descarregamento para uso pessoal, pelo que o emprego do(s) título(s) descarregado(s) para outro fim, designadamente comercial, carece de autorização do respetivo autor ou editor da obra.

Na medida em que todas as obras da UC Digitalis se encontram protegidas pelo Código do Direito de Autor e Direitos Conexos e demais legislação aplicável, toda a cópia, parcial ou total, deste documento, nos casos em que é legalmente admitida, deverá conter ou fazer-se acompanhar por este aviso.





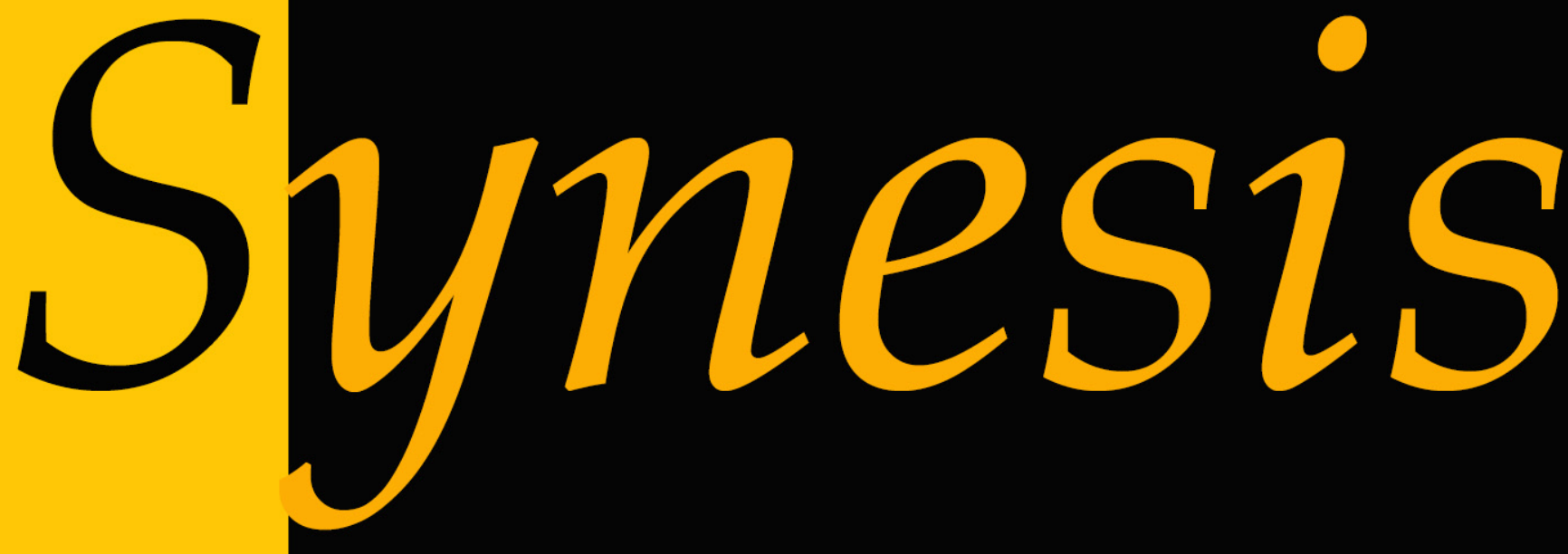

Revista do Centro de Teologia e Humanidades ISSN 1984-6754

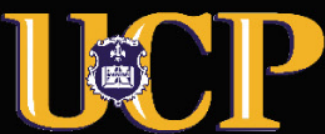




\section{NATURALISMO SEMÂNTICO: USO E ACEITAÇÃO ${ }^{1}$}

Juliano Santos do Carmo ${ }^{2}$

Resumo: Este artigo tem por objetivo geral destacar alguns aspectos fundamentais para o entendimento adequado de uma teoria do significado centrada na noção de "uso". A investigação recente tem mostrado avanços consideráveis neste sentido, e uma das tarefas deste trabalho é, assim, evidenciar ao menos uma destas importantes contribuições. A teoria do significado de Paul Horwich tem se mostrado bastante eficaz tanto no sentido de elencar as dificuldades das considerações a respeito da determinação do significado através do uso, proposta por Wittgenstein nas Investigações Filosóficas (1953), como também no sentido de oferecer soluções às objeções recorrentes que aquelas considerações enfrentam. Este trabalho tem por objetivo específico, portanto, apresentar algumas vantagens oferecidas pela abordagem de Horwich em se tratando da atribuição legítima de significado às expressões da linguagem.

Palavras-chave: Significado; Uso; Aceitação.

Abstract: This paper aims to highlight some general aspects critical to the proper understanding of a theory of meaning centered on the notion of "use". Recent research has shown considerable progress in this direction, and one of the tasks of this work is thus to show at least one of these important contributions. The Horwich's use theory of meaning has proved very effective both to rank the difficulty of the considerations concerning the determination of meaning by the use proposed by Wittgenstein in the Philosophical Investigations (1953), but also in order to offer solutions to objections applicants face those considerations. This work has the specific objective, therefore, present some advantages offered by Horwich's approach in terms of assigning meaning to legitimate expressions of the language.

Keywords: Meaning; Use; Acceptance.

\footnotetext{
1 Artigo recebido em 04/04/2012 e aprovado para publicação pelo Conselho Editorial em 22/05/2012.

2 Doutorando em Filosofia pela Pontifícia Universidade Católica do Rio Grande do Sul. Professor Auxiliar da Universidade Federal de Pelotas. Currículo Lattes: http://lattes.cnpq.br/7477981517627461. E-mail: juliano.ufpel@gmail.com.
} 
Para uma grande classe de casos - senão para todos - nos quais utilizamos a palavra 'significado' ela pode ser definida assim: o significado de uma palavra é seu uso na linguagem. ${ }^{3}$

\title{
1. Introdução
}

Atualmente existe uma grande variedade de teorias do significado que buscam compatibilizar alguns aspectos da obra do segundo Wittgenstein com as recentes descobertas da investigação filosófica contemporânea. O debate atual sobre os fenômenos reais da linguagem tem sido constantemente realimentado a partir dos desdobramentos a respeito das noções de uso, regras e correção. Desse modo, é possível afirmar que um dos novos "mantras" da filosofia contemporânea (intrinsecamente relacionado às noções de uso, regras e correção) é a ideia de normatividade do significado.

$\mathrm{Na}$ verdade, a normatividade tem sido destacada como o ingrediente essencial que divide o cenário atual entre realistas, construtivistas, reducionistas (naturalistas), instrumentalistas e céticos. A resposta ao problema da normatividade, ou ainda, ao problema de realizar a conexão adequada entre as noções de uso e correção, depende em alguma medida de um posicionamento ou da adoção de um daqueles modelos de pensamento. O pano de fundo deste debate está muitas vezes associado a uma restrição fundamental (geralmente entendida como a posição do segundo Wittgenstein): qualquer consideração puramente causal do significado estaria fadada a cometer uma petição de princípio, ou não poderia oferecer um entendimento adequado a respeito da ideia de "normatividade".

\begin{abstract}
Wittgenstein argumenta que nenhuma explicação substancial, seja do significado, seja do conteúdo mental, é possível. Não se pode oferecer nenhuma explicação que os fracione em mecanismos ou processos subjacentes. Qualquer tentativa nesse sentido ou acabará pressupondo a própria coisa que tenta explicar ou não conseguirá sustentar a normatividade do significado 4 .
\end{abstract}

Seria realmente desanimador para um amplo número de casos se esta posição fosse obrigatória, vou mostrar mais adiante que a teoria do significado como uso ${ }^{5}$, pensada nos

\footnotetext{
3 WITTGENSTEIN, L. Investigações Filosóficas. São Paulo: Abril Cultural, 1979. \43.

4 THORNTON, T. Wittgenstein: Sobre Linguagem e Pensamento. Rio de Janeiro: Loyola, 2007. pp 52-3.

5 Uma das principais objeções que a teoria do uso recebe é a acusação de que a noção de "uso" é extremamente obscura para que o significado linguístico possa ser explicitado através de uma teoria sistemática do significado. Em outras palavras, o "uso" de uma palavra seria um processo confuso ou pouco
} 
moldes de Paul Horwich ${ }^{6}$, consegue oferecer uma resposta satisfatória para esta restrição importante. Por ora, eu gostaria de chamar a atenção para alguns aspectos metodológicos. A concepção wittgensteiniana de que o significado linguístico é determinado por seu uso no contexto de um enunciado, no contexto de um jogo de linguagem, acaba por recusar toda e qualquer consideração metafísica do significado. O resultado, portanto, bastante conhecido, é o fato de que não é possível pensar a filosofia como um corpo teórico, pois o máximo que os filósofos poderiam fazer seria oferecer “observações gerais" (descrições) a respeito do significado e de suas regras de uso?

A filosofia simplesmente coloca as coisas, não elucida nada e não conclui nada. - Como tudo fica em aberto, não há nada a elucidar. Pois o que está oculto não nos interessa. Pode-se chamar também de "filosofia" o que é possível antes de todas as novas descobertas e invenções ${ }^{8}$.

A consequência mais drástica da posição de Wittgenstein para seus contemporâneos é justamente a dificuldade de encontrar uma leitura que ao mesmo tempo acomode outras duas importantes restrições: (1) que a identificação do significado com o uso seja de fato pertinente (esclarecedora) e (2) que não seja uma teoria controversa (que esteja de acordo com sua visão terapêutica da linguagem e sua perspectiva aparentemente não-teórica). Diante destas dificuldades, a única alternativa razoável seria investigar os fundamentos de uma teoria do uso em si mesma e não propriamente em sua atribuição à Wittgenstein. $\mathrm{Na}$ verdade muitos filósofos atualmente têm concentrado seus esforços neste sentido. Desse modo, este artigo não tem o objetivo de realizar uma exegese de Wittgenstein, antes, tem mais por horizonte a pesquisa sobre os mecanismos necessários

claro para que pudesse ser identificado com o significado de uma expressão. Como veremos, o trabalho de Horwich oferece boas razões para pensar que alegações deste tipo são certamente exageros e que não deveriam ser consideradas após uma breve reflexão.

6 Paul Horwich é atualmente professor da Universidade de Nova York e tem oferecido excelentes contribuições ao estudo do significado como uso. Obras de Horwich: Truth (1980), Meaning (1998), From a Deflationary Point of View (2004), Reflections on Meaning (2005) e Truth and Reality (2009).

7 As considerações do segundo Wittgenstein estavam concentradas em duas das teorias tradicionais do significado: (1) aquela que defende a idéia de que a linguagem é uma espécie de nomenclatura e que aprender uma língua equivale essencialmente a aprender a associar palavras a coisas através da definição ostensiva, e (2), a idéia de que o significado seja identificado com imagens mentais associadas a palavras. Seria correto dizer que as primeiras páginas das Investigações Filosóficas mostram a multiplicidade dos usos das palavras e dos enunciados a partir da tese de que uma expressão só tem significado no contexto de um enunciado. É importante notar que aquela idéia de que a linguagem é uma entidade discreta, que poderia ser entendida independentemente do contexto é considerada aqui como completamente superada pela idéia de que a linguagem somente pode ser entendida em seu contexto.

${ }^{8}$ WITTGENSTEIN, L. Investigações Filosóficas. São Paulo: Abril Cultural, 1973. \126. 
para o bom "funcionamento" de uma "teoria geral do uso" do que propriamente realizar uma defesa do ponto de vista wittgensteiniano.

\section{Uma teoria do significado como uso}

Após estas breves considerações a respeito da contextualização e dos limites deste trabalho, penso que seria importante ter em mente algumas características fundamentais ${ }^{9}$ de uma teoria do significado como uso, em especial aquelas que a tornam mais vantajosa explicativamente do que as demais teorias do significado, pois assim seria possível perceber os motivos pelos quais ela representa propriamente uma posição mais adequada em relação a atribuição legítima de significado. Ou seja, ter em mente as razões pelas uma teoria do uso seria preferível para realizar a tarefa de desvendar o enigma do significado.

Uma das principais características de uma teoria do significado como uso é a defesa do ponto de vista contextual, onde o significado de uma palavra é o uso dela em um contexto dado. $\mathrm{O}$ aspecto contextual do significado não é propriamente uma novidade inaugurada pela teoria do significado como uso, na verdade o "contextual” já havia sido amplamente considerado por Frege que, ciente da importância deste aspecto da linguagem, elaborou o que hoje conhecemos como o "princípio de contexto"10. Porém, este aspecto do significado certamente não causa nenhuma estranheza, pois se o significado é determinado pelo uso, então é de se supor que o contexto tenha um papel determinante nesta estrutura.

Dizer que o significado é determinado pelo uso é de algum modo dizer que o significado não é um objeto (nem mesmo pode ser considerado como constituído por objetos de um tipo especial), é dizer também que ele também não é identificado com

\footnotetext{
${ }^{9}$ Em From a Deflationary Point of View (2004), Horwich oferece uma discussão acurada sobre o modo de se entender as caracterizações mais comuns do uso linguístico. Uma hipótese seria pensar que o uso envolve noções intencionais - noções estreitamente ligadas com a noção de significado (por exemplo, 'É usado para se referir a livros'; 'É usado para expressar uma crença de que a neve é branca', etc.). No entanto, isso acarretaria negar algo que Wittgenstein defendeu fortemente: a desmistificação do significado e de seus conceitos relacionados. Por outro lado, se o uso é interpretado de modo não-intencional, então embora a tese prometa desmitificar o significado, ela não reflete a posição de Wittgenstein. A conclusão de Horwich nos leva a pensar que Wittgenstein acreditava que os critérios definitivos para que alguém utilize expressões significativamente estejam em seus próprios comportamentos, e que por isso o significado de uma palavra estaria baseado em aspectos não-intencionais de seu uso. Não deveríamos, no entanto, considerar o caráter polêmico desta idéia como um sintoma de teorização filosófica, mas sim como consequência de confusões que nos levam para longe do que está na verdade implícito em no discurso.

10 A teoria do significado fregeana defendia a posição de que "sentido" e "referência" não eram propriedades absolutas das expressões da linguagem, mas, antes, elas dependiam do contexto em que eram enunciadas. Em outras palavras, Frege defendia que se uma expressão fosse utilizada no contexto de um discurso indireto, então não teria mais um sentido e referência normais.
} 
imagens mentais (não se reduz a entes mentais), e, ainda, que o significado não é um ente de terceiro reino (como os "sentidos" de que defendia Frege). Decorre daí que o significado não é reduzido à mera referência ${ }^{11}$, como sustenta quem reduz o papel dos nomes próprios ao mero ato de fornecer a referência (o objeto denotado) ${ }^{12}$.

Os defensores deste ponto de vista salientam que o uso é observável objetivamente $^{13}$, ou seja, o significado não é uma entidade abstrata ou psíquica e, portanto, não é possível oferecer qualquer consideração reducionista que busque derivar $\mathrm{o}$ significado do conteúdo mental. Levado às últimas consequências é fácil perceber que este modelo dá origem a uma das versões mais extremas de construtivismo social, onde as atribuições legítimas de significado dependeriam de um processo altamente mecânico de aceitação social. A comunidade linguística teria o papel ativo de aceitar ou rejeitar as atribuições de significado por parte de seus usuários sem considerar qualquer instância prévia de determinação e também sem considerar qualquer regra de uso futuro.

A perspectiva comunitária é um ingrediente essencial para qualquer teoria do significado como uso, porém, a principal diferença entre as teorias do significado como uso é justamente o papel que cada teoria reserva para esta perspectiva, pois é possível assumir, por um lado, como o faz o construtivista, que a comunidade tem um papel extremamente ativo na atribuição legítima de significado (um papel que jamais se tornará ocioso); ou assumir, como o faz o realista ou o naturalista, que a comunidade tem um papel crucial

11 Uma diferença fundamental entre as teorias da referência tradicionais e as teorias contemporâneas é a seguinte: as primeiras defendem que a referência é uma relação entre falantes e objetos, entre uma expressão e aquilo que o falante quer referir-se na específica ocasião de uso; as segundas assumem que redução do papel da referência na determinação do significado deve-se justamente ao aspecto intencional que ela envolve.

12 Wittgenstein critica rigorosamente os diversos aspectos da definição ostensiva como determinante do significado linguístico. Ele mostrou que para se compreender a definição ostensiva é necessário já estar de posse de um certo tipo de noção. Por exemplo, para se compreender um enunciado do tipo "Isto é sépia" é necessário que se saiba que se está falando de uma cor e não de outra propriedade qualquer.

${ }^{13}$ Embora esta idéia remeta a algo que Quine defendeu em Pursuit of Truth, a saber: a possibilidade de se conceber orações observacionais, não deveríamos confundi-las com o que é aqui exigido pela teoria do uso. O objetivo de Quine era encontrar um tipo específico de orações, diretamente associadas com nossos estímulos, que possam atuar como elos iniciais da cadeia que conecta estímulo e teoria. Alguns exemplos deste tipo de orações seriam: "chove", "está esfriando", "é um coelho". Segundo Quine, uma oração como "os homens são mortais" é uma oração ocasional, ou seja, ela somente é verdadeira em ocasiões específicas. Mas uma oração como "chove", por exemplo, envolve uma aceitação imediata daqueles que estão envolvidos na conversa. Ele concorda que a observação possui limites imprecisos, pois envolve nossa disposição em concordar com a oração, o que por sua vez é algo que pode ocorrer em níveis distintos de sujeito para sujeito. A teoria do uso, por outro lado, exige uma identificação imediata do uso correto de uma expressão: é uma condição de significado que aquilo que é dito possa ser claramente entendido. Neste caso, se eu digo "é um coelho" quando você está apontando para uma vaca, é óbvio que algo de estranho acontece: poderia ser o caso de que eu não saiba utilizar adequadamente as palavras "coelho" e "vaca". Ambos os modelos concordariam, no entanto, quanto ao caráter da dependência do contexto: uma oração observacional está sempre condicionada a um contexto restrito. Ver: QUINE,W.V. Pursuit of Truth. Cambridge: Harvard University Press, 1992. 
apenas na determinação primitiva de significado, mas que uma vez que se apreende a regra de uso (definida pela aceitação social) a perspectiva comunitária torna-se completamente ociosa.

Desse modo, é preciso assumir uma posição a respeito do papel determinante da perspectiva comunitária e, nesse caso, a posição apresentada aqui está mais próxima de uma caracterização naturalista. Mas é possível oferecer outra posição a respeito da aceitação social: uma posição que não leva em consideração os conteúdos prévios do significado, como defende o construtivismo social, por exemplo, mas que, contra ele, defende que a aceitação não é um processo puramente mecânico onde os indivíduos dizem "sim" ou "não" para as atribuições de significados de seus companheiros. Em outras palavras, é possível conceber a "aceitação" como uma propriedade não-semântica do significado e ainda assim aceitar a existência de fatos semânticos, como defende o realismo semântico.

A teoria do significado como uso, assim, tem a peculiaridade de se manter fiel ao projeto wittgensteiniano a respeito da determinação do significado através do uso, porém distancia-se dele na medida em que supõe uma espécie de reducionismo moderado, já que prevê uma redução dos fatos semânticos a propriedades não-semânticas do significado. Vale lembrar que segundo a interpretação standard da segunda fase do pensamento de Wittgenstein, nenhuma consideração reducionista é suficientemente capaz de oferecer uma explicação razoável da compreensão de significados ou mesmo de sua estrutura normativa. Neste caso, porém, as propriedades não-semânticas fundamentais são facilmente captáveis através uma concepção peculiar da ideia de aceitação, uma concepção que segue de perto o modelo defendido por Paul Horwich em Meaning (1998).

Este modelo defende a ideia de que existem determinadas propriedades do significado, ou seja, características que determinam ou revelam o significado de uma palavra. Para usar um exemplo semelhante ao de Horwich ${ }^{14}$, pense no fato de que um determinado som tem em português as características distintivas que determinam ou revelam a palavra "macaco" (ou ainda o significado que "macaco" tem em português); outro som tem a mesma propriedade em inglês; assim como outras palavras em português possuem outras propriedades de significado, e assim por diante. Em sua versão mínima, a teoria do significado como uso de Horwich procura mostrar como determinados sons significam o que eles significam. Porém, a teoria do significado como uso pode ser

${ }^{14}$ HORWICH, P. Reflections on Meaning. New York: Oxford, 2005. pp 1-2. 
facilmente expandida para tratar de aspectos mais complexos em relação à atribuição legítima de significado.

As propriedades do significado, como aquelas evidenciadas no parágrafo anterior, são por natureza complexas. Ou seja, tais propriedades podem ser analisadas em termos de propriedades mais simples ou constituintes ${ }^{15}$. Considere, por exemplo, a propriedade "zinco". O elemento químico "zinco" (enquanto propriedade complexa) possui a propriedade mais simples (básica) " $\mathrm{Zn}_{30}$ " que, por sua vez, tem a propriedade mais simples “30 prótons e 30 elétrons", que por sua vez teria a propriedade mais simples "massa atômica 65,4", e assim por diante. É possível, assim, mostrar que todas as propriedades do significado poderiam resultar de uma propriedade constituinte, ou propriedade mais básica.

Esta caracterização das propriedades do significado poderia dar a entender uma posição equivocada daquela que realmente está sendo pressuposta aqui. A teoria do significado como uso não pressupõe uma espécie de atomismo lógico radical como aquele defendido por Wittgenstein no Tractatus Logico-Philosophicus (1921), mas, antes, defende apenas que as propriedades complexas do significado podem ser reduzidas naturalmente a propriedades mais básicas que explicam os motivos pelos quais identificamos certas características como "zinco", por exemplo. Outra característica desta posição é o fato de que as propriedades básicas do significado são completamente não-intencionais. O objetivo da abordagem naturalista a respeito do significado como uso é muito semelhante, em alguma medida, ao objetivo de Jerry Fodor:

O que queremos no mínimo é algo da forma "R representa $S$ " é verdadeiro se e somente se $\mathrm{C}$, onde $\mathrm{o}$ vocabulário no qual a condição $\mathrm{C}$ foi fraseada não contém nem expressões intencionais nem expressões semânticas ${ }^{16}$.

As propriedades básicas não-intencionais do significado são evidenciadas através de regularidades básicas de uso, ou seja, não passam de generalizações a respeito das circunstâncias pelas quais palavras são proferidas. Temos, portanto, uma explicação plausível para dois fenômenos linguísticos importantes: a teoria explica quando determinadas palavras são utilizadas e, inversamente, através do modo como as palavras são utilizadas ela explica o que elas significam. Sendo assim, as regularidades básicas de uso

\footnotetext{
${ }^{15}$ HORWICH, P. Reflections on Meaning. New York: Oxford, 2005. pp 26-7.

${ }^{16}$ FODOR, J. A theory of Content and Other Essays. Cambridge: MIT Press, 1991. p. 32.
} 
explicam naturalmente as características indicativas de uma propriedade de significado e, assim, satisfazem as condições que compõem a propriedade ${ }^{17}$.

\section{Propriedades básicas do significado}

É fácil perceber que a teoria do significado tem um grande potencial de resolver ou pelo menos evitar algumas objeções fortes que as teorias contemporâneas do significado em geral recebem. Porém, é necessário precisar aqui o que exatamente está subentendido na expressão "propriedade básica", pois assim será possível mostrar o real poder explicativo desta posição. Uma propriedade básica do significado é aquilo que Horwich chama de "propriedade de aceitação", dito em outros termos, as regularidades básicas de uso refletem instâncias sob as quais determinadas sentenças são aceitas ou ainda consideradas verdadeiras. Pense nos seguintes exemplos:

(a) Pedro aceita (onde "aceitar" é tomada uma atitude psicológica sem conteúdo) a proposição "isto é vermelho" em circunstâncias determinadas como, por exemplo, quando está na presença de coisas evidentemente vermelhas.

(b) Pedro tem uma tendência em aceitar proposições da forma " $p$ é verdadeiro se e somente se $p$ "18.

Desse modo, é possível mostrar que certas regularidades básicas de uso são regidas por determinadas propriedades de aceitação. Aceitar uma proposição é, portanto, uma atitude não-intencional em face de determinadas circunstâncias de uso. Mais especificamente, a propriedade de uso de uma palavra é explicada em termos do fato de aceitarmos certas frases específicas que a contêm. Para cada palavra, há uma "regularidade básica de uso". "Aceitar” uma frase é supostamente uma noção psicológica, e não uma forma reconhecível de comportamento social efetivo ${ }^{19}$.

Em Reflections on Meaning (2005), Horwich oferece uma série de exemplos a respeito daquilo que estamos chamando aqui de propriedade básica ou propriedade de aceitação. $\mathrm{Na}$ verdade, embora a nova versão apresentada possa ser pensada como uma re-elaboração dos aspectos centrais da teoria do significado como uso, ela não altera substancialmente o

\footnotetext{
${ }^{17}$ HORWICH, P. From a Deflationary Point of View. New York: Oxford University Press, 2004. p. 68.

${ }^{18}$ HORWICH, P. Meaning. New York: Oxford, 1998. p. 95.

19 Horwich defende que mesmo as expressões individuais possuem significados: a "propriedade do significado", como já dissemos, é seu uso reger-se por tal e tal regularidade — ou, mais especificamente, a propriedade de todo o uso da palavra se explicar em termos do fato de aceitarmos certas frases específicas que a contêm. Para cada palavra, há uma "regularidade básica de uso". Neste ponto específico, Horwich parece se afastar de Wittgenstein e de Brandom. Wittgenstein não aceitaria noções psicológicas na determinação do significado e Brandom defenderia que uma expressão isolada não possui significado, ou melhor, ela só possui significado derivadamente, pois depende do significado de uma frase completa.
} 
projeto defendido em Meaning (1998), pois basicamente a teoria do significado como uso permanece com o objetivo de mostrar que para cada palavra da linguagem existe uma propriedade de aceitação que rege seu uso, ou seja, a propriedade de aceitação funciona como uma espécie de regra que determina as condições de nossa aceitação de certas sentenças específicas $^{20}$. Considere os seguintes exemplos:

"Verdade" significa o que significa para nós em virtude do fato de que a regra que governa seu uso diz respeito ao fato de que estamos preparados a provisoriamente aceitar qualquer instância do esquema " $<$ p $>$ é verdadeiro $\leftrightarrow$ p".

O significado de "solteiro" é engendrado pelo fato de que sua regularidade básica de uso diz respeito a nossa aceitação da sentença: "os solteiros são homens não casados".

O significado de "vermelho" é derivado do fato de que sua regra de uso é nossa tendência em aceitar "isto é vermelho" em resposta ao tipo de experiência visual normalmente provocada pela observação de uma superfície claramente vermelha.

O significado de "água" é constituído pelo fato de que a regra que explica seu emprego geral é que aceitamos que "x é água $\leftrightarrow \mathrm{x}$ tem como natureza subscrita o material de nossos mares, rios, lagos e chuva" 21 .

O que é imediatamente evidente neste modelo é o fato de que as regularidades básicas de uso ou mesmo as propriedades de aceitação não são explicitamente formuladas, já que para todos os casos seria possível encontrar uma propriedade não-semântica (aceitação) que oferece uma regra de emprego geral. O modelo permanece, portanto, coerente com seus objetivos iniciais: oferecer uma consideração naturalista-redutiva que dê conta de noções misteriosas relacionadas ao processo de atribuição legítima de significado através da identificação de regularidades básicas de uso.

Dito o mínimo a respeito do modo como o uso se relaciona com a noção de aceitação, é possível perceber agora algumas vantagens que essa forma peculiar de reducionismo semântico oferece em relação às demais teorias do significado como uso. Dizer que a propriedade de aceitação é uma atitude não-intencional é dizer, entre outras coisas, que com isso fica em aberto uma possibilidade naturalista de explicar o modo como a intencionalidade surge de propriedades não-intencionais. A redução de fatos semânticos a propriedades não-semânticas do significado oferece também o importante benefício de explicar de um modo bastante plausível como surgem fatos semânticos.

\footnotetext{
${ }^{20}$ HORWICH, P. Reflections on Meaning. New York: Oxford, 2004. p. 94.

${ }^{21}$ HORWICH, P. Reflections on Meaning. New York: Oxford, 2004. pp. 26-7.
} 
Este modelo de teoria do significado como uso, portanto, difere radicalmente do construtivismo social, pois prevê a existência de fatos semânticos e ao mesmo tempo oferece uma concepção razoável do modo como eles surgem a partir de propriedades nãosemânticas. Todas as propriedades semânticas poderiam licitamente ser reduzidas a propriedades não-semânticas através da identificação de certas regularidades básicas de uso. Este modelo difere, também, em alguma medida do realismo semântico, já que este supõe uma concepção de verdade como correspondência (incompatível, a princípio, com nosso modelo) e nem sempre consegue explicar adequadamente o modo como surgem de fatos semânticos. A teoria do significado como uso apresentada aqui explica, assim, como surgem os fatos a respeito do significado e como eles devem ser compreendidos sem pressupor com isso qualquer conteúdo conceitual ou intencional das palavras da linguagem.

É importante lembrar que uma das metas do naturalismo era justamente mostrar que certos processos misteriosos possuem uma fundamentação completamente nãomisteriosa. Nesse caso, é possível oferecer uma consideração a respeito do significado que não envolve, necessariamente, uma teoria representacional, ou seja, uma teoria que justifique o modo como a linguagem é suficientemente capaz de representar a realidade. Note que para explicar este ponto a teoria precisa mostrar apenas que a referência não é o que determina o significado das expressões, logo a correspondência ou mesmo a verdade não possui uma relação essencial com a noção de significado. $\mathrm{Na}$ verdade, a teoria do significado defendida aqui está fortemente comprometida com uma visão deflacionária específica $^{22}$.

A teoria do significado como uso tem ainda uma vantagem fundamental em relação às demais teorias do significado: ela prevê que o significado linguístico é uma noção inteiramente não-normativa. Ou seja, ela oferece uma explicação razoável a respeito de um problema importante na contemporaneidade. Mas como ela faz isso? Primeiramente é necessário compreender que há uma diferença substancial entre a suposição de uma "normatividade intrínseca" e a mera "implicação normativa" do significado. Isto quer significar que é possível explicar a aparência de normatividade intrínseca apenas pelas considerações de uma implicação normativa de um enunciado. Note que a teoria defendida aqui não nega a existência de proposições normativas, pelo contrário, ela defende apenas que tais proposições podem ser explicadas de outro modo.

${ }^{22}$ HORWICH, P. From a Deflationary Point of View. New York: Oxford, 2005. 
Certas consequências normativas surgem do fato de que uma expressão tenha um significado particular. Por exemplo, dado que a palavra "cão" significa, seria correto aplicá-la para certas coisas e errado aplicá-la a outras. (...) Conceder que o significado tenha consequências normativas não é o mesmo que conceder que as propriedades do significado sejam intrinsecamente normativas ${ }^{23}$.

O "quadro referencial teórico" de Horwich, portanto, caracteriza-se pela defesa de um ponto de vista deflacionário, pois, com efeito, há um deslocamento do eixo da investigação do significado centrado na verdade para aquilo que está implícito na utilização de palavras na linguagem. Com efeito, este parece ser um dos ingredientes mais chamativos de seu pensamento, pois permite empreender uma maneira completamente inovadora de interpretar e resolver aquelas dificuldades. A teoria do significado como uso, pensada nestes moldes, acaba por oferecer uma resposta satisfatória para uma ampla classe de problemas relevantes, cuja tradição filosófica responsável por eles não conseguiu oferecer mais do que uma série de observações conflitantes, que mais propriamente proporcionou um acúmulo de constrangimentos ao invés de um tratamento adequado do significado linguístico.

O potencial da noção de "uso", como determinante do significado, torna-se assim o paradigma dominante nas considerações contemporâneas. Isso mostra, entre outras coisas, que o pensamento de Wittgenstein permanece extremamente atual no que se refere a resolução daquilo que em geral chamamos de "enigma do significado". A noção de uso é suficientemente capaz de oferecer uma explicação razoável dos motivos pelos quais uma palavra em português (macaco, por exemplo) possui um significado específico que o distingue de outras palavras (jacaré, por exemplo). O que caracteriza as expressões da linguagem é o fato de que elas possuem regularidades básicas de uso (propriedades constituintes de significado).

\section{Conclusão}

A suposição de que as propriedades semânticas podem ser legitimamente reduzidas a propriedades não-semânticas é facilmente explicada a partir do fato de que para especificar uma propriedade de aceitação ninguém diria algo como: "aceitação" é utilizada para se referir à aceitação. É importante ter em mente que o ponto alto da discussão

${ }^{23}$ HORWICH, P. Meaning. New York: Oxford, 1998. p 37. 
naturalista é a desmistificação do significado e de suas noções afiliadas, caracterizando-os de tal modo que suas relações explicativas para com o comportamento verbal se tornem compreensíveis.

As propriedades do uso, nesse caso, são facilmente detectáveis, ou seja, é possível identificar na linguagem de Pedro, por exemplo, se ele compreende ou não uma palavra através do modo como ele a utiliza. Portanto, não é possível admitir como uma propriedade do uso aquelas propriedades não detectáveis linguìsticamente. Como ressalta Horwich, é por isso que uma propriedade tal como "associada a tais e tais atividades cerebrais" não poderia ser uma propriedade do uso; ao passo que a propriedade "aplicada na presença de coisas vermelhas" poderia.

Esta é apenas outra maneira de dizer que a noção de "uso" não precisa estar restrita às inferências ${ }^{24}$ ou a outros fenômenos estritamente internos. É certo, no entanto, que para muitos casos o significado de uma expressão pode ser determinado por regularidades do uso puramente internas (como parece ser o caso da verdade, por exemplo), mas na maioria dos casos, diz Horwich, ele é determinado por uma regularidade externa (a identificação de cores, por exemplo, parece remeter a uma afetação externa).

Por fim, note que a teoria do uso pensada nos moldes de Horwich tem como especificidade o fato de que por pressupor que as regularidades do uso não são explicitamente formuladas e nem mesmo deliberadamente seguidas como regras, ela evita qualquer objeção em razão de circularidade viciosa, já que a idéia de regularidade de uso não é caracterizada utilizando-se do próprio termo ${ }^{25}$. A regularidade do uso de uma palavra transmite sua ocorrência às ocorrências de outras palavras. Ou seja, as regularidades que governam a aplicação de diferentes palavras não são inteiramente separadas umas das outras. É por isso que em uma proposição a regularidade do uso diz respeito a todas as suas expressões constituintes. A composicionalidade do significado é um problema clássico

\footnotetext{
${ }^{24}$ Toda argumentação é constituída tipicamente por uma inferência ou mesmo por uma série delas. Usa-se o termo inferência para se falar do ato de passar das premissas às conclusões segundo determinadas regras e também para se falar da estrutura desta passagem. Muitos filósofos buscaram explicitar algumas dessas regras, em especial aquelas regras que, tendo em vista a verdade das premissas, garantem a verdade da conclusão. Uma boa introdução ao inferencialismo pode ser encontrada em BRANDOM, R. Making it Explicit. Cambridge: Harvard University Press, 1994.

25 É óbvio que a teoria do significado como uso enfrenta uma série de objeções a respeito da ideia de "aceitação", até por que a "aceitação" é um tema recorrente e complexo geralmente atribuído ao construtivismo social. Eric Swanson, por exemplo, discorda em vários aspectos da teoria de Horwich, em especial quanto à propriedade (ou condições) de aceitação. Para ele este termo técnico deve ser mais bem explicado, a mera caracterização desta propriedade como uma relação psicológica entre uma sentença e o uso que dela é feito não é suficiente para fornecer um entendimento adequado do significado.
} 
endereçado às teorias do significado, porém, não vou desenvolvê-lo aqui, pois seria preciso muito mais espaço para que ele fosse corretamente esboçado

Não há, portanto, uma única propriedade que dê conta de todos os significados da linguagem, em outras palavras, não existe uma propriedade uniforme que constitua todas as relações do significado. Existem, no entanto, regularidades básicas que são potencialmente capazes de explicar o uso de todas as palavras. Um exemplo de tais regularidades é revelado pela "propriedade da aceitação", que varia de acordo com o tipo de expressão cujo significado está sendo explicado. Depende se estamos interessados em explicar o significado de "macaco", "tijolo" ou "neutrino", por exemplo.

O grande mérito da teoria do significado como uso, defendida por Horwich, é justamente mostrar que o fracasso de algumas teorias do significado se deve a uma supervalorização dos conceitos de "referência" e "verdade". Wittgenstein já havia acenado nas Investigações Filosóficas que a "referência" não tem o papel que os filósofos costumam atribuir a ela. A teoria do significado como uso desloca o eixo de investigação para uma esfera das regularidades básicas dos usos linguísticos, onde certamente os conceitos de referência e verdade não ocupam um papel central. 


\section{Referências Bibliográficas}

BRANDOM, R. Making it Explicit. Cambridge: Harvard U. Press, 1994.

CANFIELD, J. Philosophy of Meaning, Knowledge and V alue in the Twentieth Century. New York: Routledge, 1997.

GLOCK, H. J. Wittgenstein. Rio de Janeiro: Jorge Zahar Editor, 1996.

GRICE, H.P. Studies in the Ways of Words. Cambridge: Harvard U. Press, 1989.

HORWICH, P. From a Deflationary Point of View. New York: Oxford U. Press, 2004. , Meaning. New York: Oxford U. Press, 1998. , On Meaning. New York: Oxford U. Press, 2005.

QUINE, W.V. Pursuit of Truth. Cambridge: Harvard University Press, 1992.

SOAMES, S. Reference and Description. New Jersey: Princeton U. Press, 2005.

WITTGENSTEIN, L. Investigações Filosóficas. São Paulo: Abril Cultural, 1979. 